\title{
Is Testimonial Injustice Epistemic? Let Me Count the Ways
}

\author{
Manuel Almagro Holgado, Llanos Navarro Laespada and Manuel de Pinedo García \\ Department of Philosophy I, Edificio Facultad de Psicología, Campus de la Cartuja, University of Granada, \\ Granada, Spain. \\ Corresponding authors. manueldepinedo@gmail.com
}

(Received 26 May 2019; revised 27 September 2020; accepted 15 October 2020;

first published online 3 November 2021)

\begin{abstract}
Miranda Fricker distinguishes two senses in which testimonial injustice is epistemic. In the primary sense, it is epistemic because it harms the victim as a giver of knowledge. In the secondary sense, it is epistemic, more narrowly, because it harms the victim as a possessor of knowledge. Her characterization of testimonial injustice has raised the following objection: testimonial injustice is not always an epistemic injustice, in the narrow, secondary sense, as it does not always entail that the victim is harmed as a knowledge-possessor. By adopting a perspective based on Robert Brandom's normative expressivism, we respond to this objection by arguing that there is a close connection, conceptual and constitutive rather than merely causal, between the primary and the secondary epistemic harms of testimonial injustice, such that testimonial injustice always involves both kinds of epistemic harm. We do so by exploring the logic and functioning of belief and knowledge ascriptions in order to highlight three ways in which the secondary epistemic harm caused by testimonial injustice crystallizes: it undermines the epistemic agency of the victim, the epistemic friction necessary for knowledge, and the possibility of occupying particular epistemic nodes.
\end{abstract}

In Epistemic Injustice, Miranda Fricker characterizes testimonial injustice as an injustice of an epistemic kind. According to her, testimonial injustice consists of a systematic and persistent credibility deficit caused by identity prejudices that wrong the victim in her capacity as a knower (Fricker 2007, 4, 20, 27-29). ${ }^{1}$ Against this, the following objection has been leveled: although it is obvious that there is injustice involved, it is unclear that the injustice is of an epistemic kind, because disbelief on the part of one or more hearers does not necessarily make the speaker lose her knowledge or cease to trust her own belief $^{2}$ (see Hawley 2011; Pohlhaus Jr. 2014; Engel 2016; Origgi and Ciranna 2017). It is easy to think of cases where one is subjected to this kind of injustice without losing knowledge or even confidence in one's beliefs.

Of course, possessing knowledge is not the only aspect of our epistemic life. In fact, Fricker distinguishes between primary and secondary epistemic harms caused by testimonial injustice. Primarily, the harm suffered by those who, because of their social

(c) The Author(s), 2021. Published by Cambridge University Press on behalf of Hypatia, a Nonprofit Corporation. This is an Open Access article, distributed under the terms of the Creative Commons Attribution licence (https://creative commons.org/licenses/by/4.0/), which permits unrestricted re-use, distribution, and reproduction in any medium, provided the original work is properly cited. 
identity, don't receive the credibility that they deserve affects them as givers of knowledge. This kind of harm, which is clearly epistemic, is independent of the confidence that the subject of injustice has in her beliefs and from her capacity to retain knowledge in the face of prejudice. However, the objection that questions the epistemic character of testimonial injustice does not negate this primary kind of harm, but the secondary, more purely epistemic one: the harm to the victim as a possessor of knowledge. This secondary harm is more complex, and the way Fricker presents it, it includes practical and epistemic elements. Some of the examples that Fricker presents of the practical dimension of the harm are, to our mind, also epistemic: for instance, if we are victims of persistent injustice, we may end up losing the necessary confidence in our own ideas (or, at least, giving that impression), which in turn may lead to others having reasons not to trust our judgment and testimony, something that could cause further primary harms as givers of knowledge. The objection, however, is directed at what Fricker presents as the "more purely" epistemic harm:

the recipient of a one-off testimonial injustice may lose confidence in his belief, or in his justification for it, so that he ceases to satisfy the conditions for knowledge; or, alternatively, someone with a background experience of persistent testimonial injustice may lose confidence in her general intellectual abilities to such an extent that she is genuinely hindered in her educational or other intellectual development. (Fricker 2007, 47-48; see also Pohlhaus 2017, 13-14)

The objection claims that the more purely epistemic harm need not happen: inasmuch as someone who suffers from a one-off testimonial injustice retains her belief and her justification, or someone subjected to persistent testimonial injustice retains her intellectual self-confidence, she will be unjustly deprived of her epistemic rights as a provider of knowledge but not as a possessor of knowledge. In other words, against Fricker's claim, the objection goes, the primary harm will not cause the secondary harm. Given that Fricker takes the secondary harm to be extrinsic to, and caused by, the primary harm, rather than being a proper part of it, the objection aims at cutting the causal chain between losing our status as givers of knowledge and losing our status as knowledge-possessors. Our central objective in this article is to respond to the challenge by means that are not at Fricker's disposal: ${ }^{3}$ if we can show that there is a conceptual, rather than merely empirical, connection between having knowledge and being attributed with having knowledge, the link between the primary and the secondary harm will cease to be causal. There will be no principled reason to take the secondary harm to be extrinsic to the first and, furthermore, both harms will emerge as two sides of the very same epistemic injustice.

We will argue that the cases of testimonial injustice where the victim is able to overcome the credibility deficit turn out to be marginal and, what is more important, derivative if we shift our focus toward the meaning and function of the verb "to know." Although we also depart from Fricker in favoring a more structural and public understanding of knowledge-possession than her more psychological and private one and, hence, give more weight to the constitutive role that knowledge-attribution plays for knowledge-possession, our central strategy is to move the discussion to a metaepistemological arena, where "meta" is to be understood in analogy with meta-ethics: we put at the center of our account an analysis of the meaning of knowledgeattributions and of what we do when we attribute knowledge to someone. This contrasts with Fricker's interest in "first-order" epistemology, as shown, for instance, in her 
partial reliance on virtue epistemology. Rather than framing the issue in terms of the social conditions under which someone receives knowledge-attributions, we argue that concentrating on what we do in attributing knowledge to others shows more clearly that testimonial injustice retains its epistemic character even in those cases in which the victim overcomes the credibility deficit. According to this meta-epistemological framework, there is an essential conceptual link between having knowledge and being attributed with having knowledge. We analyze the meaning of "knowing" by focusing on contexts where it is normally used. We do this by exploring what follows from saying that someone knows that $p$ and from what someone's knowing that $p$ follows. This way, we show that if we prevent a person, one way or another, from participating in certain knowledge-related contexts, we facilitate her not knowing. Given that from the firstperson perspective, knowledge and mere belief are indistinguishable, ${ }^{4}$ not attributing knowledge to someone is a way of making it easier for that person not to know. When we say of someone that she knows or believes that $p$, we are, among other things, attributing merit, granting a normative status and acquiring certain conceptual commitments linked to action, and we do that in virtue of the connection between "know" and certain practices. Furthermore, seeing knowledge-attributions in a normative light makes it easier to realize that epistemic injustices exploit unjust social norms, independently of the existence of biased psychological mechanisms, and makes it easier to see why the epistemic harm to which the objection is directed (the harm that Fricker calls secondary) depends on the harm of not being considered as a reliable source of knowledge (Fricker's primary harm). Although it is not our purpose to argue for a structural (Ayala and Vasilyeva 2015; Haslanger 2015a; 2015b; Ayala 2018) approach in this article, we do emphasize that changing our focus from psychological factors to unjust public norms and practices makes more salient the cases where the harm is epistemological in the secondary sense. In this sense, the meta-epistemological analysis enables us to show that Fricker's diagnosis of testimonial injustice is immune to such an objection: in our view, knowing that $p$ is not a state a subject can be in (like, for instance, having a high level of cholesterol) regardless of being recognized or not as knowing by other members of the community; it is, rather, a socially granted status. Unjustly and systematically receiving a credibility deficit is, to keep the disanalogy, not just being misdiagnosed with lack of knowledge given the essential link between attribution and possession of knowledge.

Based on the meta-epistemological turn, we distinguish three ways in which testimonial injustice wrongs the capacity to know of those who suffer it by facilitating the occurrence of further epistemic harms, even in the narrow sense of "epistemic": (i) as far as the victim is concerned, as Beate Roessler has highlighted, her very epistemic agency may be damaged (Roessler 2015), that is, a systematic and persistent credibility deficit may damage the self-worth and the self-knowledge of the victim, and both are prerequisites for autonomy; (ii) regarding the community, not being allowed to participate in the public game of asking and giving testimony robs the subject of the epistemic friction that is necessary to be a knowing subject. This can happen in a variety of ways: for instance, she may be ignored when it comes to lofty subjects, or she can be contradicted or corrected randomly, regardless of what she says; and (iii) even more important, the subject will not be able to occupy crucial epistemic socio-normative nodes, which is a structural injustice that is independent of whether she herself feels qualified to occupy them (assuming she has been able to avoid the harm pointed out in [i] or whether she has found a way to overcome the limitations pointed out in [ii]). 
The article has four parts. In section I, we introduce the notion of testimonial injustice and present the objection. In section II, we focus on the meaning and the role that the concept of knowledge plays in our practices as a community. Section III identifies three different ways in which testimonial injustice may cause an epistemic harm. Section IV concludes the article.

\section{Testimonial Injustice and the Epistemic Challenge}

Let us start by recalling Fricker's characterization of testimonial injustice. Testimonial injustice is a kind of epistemic injustice that occurs when identity prejudice causes a hearer to give a deflated level of credibility to a speaker's word (Fricker 2007, 1). The central kind of case in which testimonial injustice occurs is when the speaker who gives testimony is given a credibility deficit because the hearer has a prejudice against the speaker's social identity. The idea is that the speaker tells someone something, and the hearer, at some cognitive level, links a salient aspect of the speaker's social identity to a discrediting trait, which makes the speaker less credible to the hearer than the speaker deserves. These prejudices question the competence or sincerity of the speaker (Fricker 2007, 45), so that the victim of testimonial injustice may be taken to be less competent or less trustworthy than she ought to be.

Fricker discusses in her book two well-known literary examples of testimonial injustice. The first comes from Harper Lee's classic novel, To Kill a Mockingbird. Robinson, an African-American man, is accused of raping a white woman, Mayella Ewell, and must testify before a jury of white people. Because of the jury members' prejudice against African Americans, the jury does not believe Robinson's testimony, even though he is clearly innocent. Robinson ends up in jail for a crime he did not commit. The second case takes place toward the end of Anthony Minghella's screenplay for The Talented Mr. Ripley. Marge Sherwood, a woman, expresses her suspicion that Ripley is Dickie's killer, and then Herbert Greenleaf, a man, rejects her testimony by saying: "Marge, there is female intuition, and then there are facts." The idea is that Herbert gives Marge less credibility than she deserves because of the prejudice that women's claims are more emotional than rational.

These cases of testimonial injustice are unjust because their victims receive less credibility than they deserve simply because they belong to a particular social group. They are testimonial because the victim receives less credibility after giving testimony, that is, after trying to share information through a claim. But in which sense are they epistemic? What exactly does it mean that testimonial injustice is epistemic?

Generally speaking, epistemic injustice is, according to Fricker, a kind of injustice in which someone is wronged specifically in her capacity as a knower (Fricker 2007, 1, 20). The particular way in which testimonial injustice does this is that a hearer wrongs a speaker in her capacity as a giver of knowledge, as an informant (Fricker 2007, 5, 44). Along with this primary harm that testimonial injustice causes, Fricker points to a secondary harm that testimonial injustice may cause. As a result of the credibility deficit, the victim of a one-off episode of injustice may abandon her commitment to the belief that $p$ that she was trying to communicate to the hearer, or she may abandon her commitment to the reasons supporting that belief, so that she would cease to satisfy the conditions for knowledge that $p$. Likewise, from a diachronic point of view, a person with a background experience of persistent testimonial injustice might lose confidence in her epistemic abilities, which would not only diminish her capacity to communicate true and justified beliefs, but also her ability to evaluate beliefs and reasons and 
discriminate among them and, consequently, her ability to retain a strong and resistant system of knowledge.

In the following pages, we present the objection to the epistemic nature of testimonial injustice suggested by some authors (Hawley 2011; Pohlhaus 2014; Engel 2016; Origgi and Ciranna 2017). The idea is that although it is indisputable that there is injustice involved when testimony is given a credibility deficit because of the speaker's social identity, it is not obvious that the injustice is of an epistemic kind, in the sense of the secondary, purely epistemic harm noted by Fricker.

Let's imagine the case of a rape victim whose testimony is not believed because she belongs to an oppressed group. Fricker's critics argue that if, after being disbelieved, the rape victim retains her belief about what happened, then her knowledge is not undermined by the testimonial injustice, and therefore, that episode of testimonial injustice is not epistemic in the secondary sense. Of course, in the primary sense of "epistemic," the injustice is epistemic: the victim cannot convey her knowledge to these particular hearers, and then she cannot participate in that practice of sharing knowledge. She is harmed in her dignity as a knowledge-giver. However, in the narrower and secondary sense where a harm is epistemic just in case it undermines the subject's knowledge, the injustice is not epistemic: the victim retains her knowledge, she still knows what happened and who the rapist was despite the hearers not believing her. In this secondary sense, it seems that testimonial injustice would be epistemic only sometimes, that is, only in those cases in which the speaker reacts to the testimonial injustice by giving up on the belief that she expressed through her testimony. Gloria Origgi and Serena Ciranna raise the objection even more strongly:

But is this wrong an epistemic wrong? Who is epistemically hurt? It seems that the receiver of information, due to her biases and prejudices, will end up with less information than she would have had if she had considered the speaker at her face value instead of applying biased filters to her credibility assessment. . . . By harming herself epistemically, she clearly harms also the speaker morally or socially, lowering her status as a less authoritative knowledge giver. However, she does not harm her epistemically, because if the informant knows the truth and she is not believed, she will go on knowing the truth, that is, her knowledge would not be diminished. (Origgi and Ciranna 2017, 304)

According to Origgi and Ciranna, not only is it unclear that the testimonial injustice causes secondary epistemic harm to the victim, but it can also be argued that the epistemic harm is actually suffered by the person who commits the testimonial injustice: because of his biases and prejudices, the perpetrator of the testimonial injustice ends up with less information than he could have obtained, whereas the victim still knows what happened.

From Fricker's view the response to this criticism is, in a sense, trivial: every case of testimonial injustice is epistemic, not necessarily in virtue of a loss of knowledge on the part of the victim, but in virtue of the victim being hindered as a giver of knowledge. However, this response is not sufficient. The response that trivially follows from Fricker's view has the virtue of indicating a sense in which testimonial injustice is epistemic in every case, but concedes to critics that the epistemic harm that Fricker calls secondary does not depend directly or immediately on the primary harm, in the sense that not every primary harm is necessarily accompanied by the secondary one. Instead, the secondary harm occurs only sometimes: only to the extent that the victims 
react to testimonial injustice by questioning their own beliefs. In our view, there are at least two problems here.

The first problem is of a strictly political nature. Arguing that the impact of the secondary epistemic harm does not depend directly on the testimonial injustice-or on the primary harm it causes-but rather on the victim's reaction to it may lead to the victim being blamed for the wrong done to her capacity as a knower in those cases where there is a loss of knowledge. Suppose that $S$ has lost her confidence in $p$ as a result of $H$ doubting her credibility. When the abandonment of the belief that $p$ turns out to be a loss of knowledge, someone might reproach $S$ for having trusted $H$ more than herself. That is, the idea that the connection between the primary and the secondary harm is mediated by the victim's psychology suggests that at least a part of the epistemic harm done to her is because of her insufficient self-confidence or self-esteem. Furthermore, if she retains her belief and confidence, this could also be blamed on the epistemic vice of imperviousness to others' opinions and reasons. From the perspective we adopt, the two harms that Fricker calls primary and secondary are not independent, but rather two sides of the same coin. From this point of view, the secondary harm done to a speaker's knowledge is an immediate and necessary consequence of testimonial injustice and is the exclusive responsibility of the person who commits it. Even the most conscientious among us are liable on occasions not to accept that they have committed a testimonial injustice, which makes it all the more urgent for us to offer an account that no person, however unreasonable or prejudiced, could use as a tool to evade responsibility or to place an obligation on the victim to present heroic epistemic resistance in order not to be accused of bringing the secondary harm on herself.

The second problem is of a philosophical or conceptual nature. The idea that the connection between the primary and the secondary harm is possible but not necessary suggests that testimonial injustice could harm its victims only in their capacity as givers of knowledge, without this affecting other aspects of their being subjects of knowledge, for instance, their being knowledge-possessors. In other words, it suggests that victims of testimonial injustice could be full subjects of knowledge (that is, knowledgepossessors as well as knowledge-givers), apart from their ability to communicate their knowledge. Their problem would then be a difficulty in communicating a system of knowledge that nevertheless remains intact. From the perspective that we favor, it is conceptually impossible that the wrong done to someone in her capacity as a giver of knowledge does not affect her ability to evaluate, discard, and select beliefs, and, therefore, it is impossible that the primary harm does not also wrong the victim as a subject of knowledge in the sense of the secondary harm. Here, once again, we are relying on how deeply knowledge, in contrast with other goods, is connected to social practices of attribution. For instance, someone may inherit a house without being able to sell it as long as someone else, its usufructuary, lives, or, similarly, it may not be possible for me to give you the tree in my garden because it is too deeply rooted or because it is listed as protected by the local council. These are cases where owning a thing is not conceptually linked to being able to sell it or give it away. In contrast, we argue that possessing knowledge and being recognized as a giver of knowledge are conceptually tied. The normative concept of knowledge that we present is such that having knowledge is not like having a house, but rather like having the capacity to do certain things, central among them being the socially recognizable capacity to give testimony. Conceptually speaking, there is no gap between being evaluated as someone who knows such and such and being someone who knows such and such. Having knowledge is nothing but being recognized by (part of) the community as someone who not only believes that $p$, but also 
deserves the merit of believing it with truth, that is, knowing that $p$. This is not to say that there cannot be particular episodes of testimonial injustice where the victim tries to communicate her knowledge that $p$ and, after not being believed, she continues to believe and therefore to know that $p$. The idea is rather that testimonial injustice, because of its persistent and systematic nature, forces a holistic and diachronic perspective from which it is untenable that victims can be harmed as knowledge-givers without this also harming their ability to sustain a stable system of knowledge by normal epistemic means.

\section{The Meta-Epistemological Turn}

Our thesis is that testimonial injustice is epistemic in the twofold sense that it necessarily causes primary and secondary harms to its victims, even in those cases where the speaker does not abandon her belief. To show this, we suggest analyzing what it means to have knowledge by focusing on the role that the concept of knowledge plays in our practices as a community. That is, we suggest understanding testimonial injustice not from the epistemological point of view usually favored by Fricker and her critics, but from a meta-epistemological point of view. We argue that this change of focus not only shows that testimonial injustice is also secondarily harmful in every case, but also that the cases where testimonial injustice does not entail a loss of confidence on the part of the speaker are conceivable only as marginal and, what is more important, derivative.

The meta-epistemological perspective that we suggest is based on the normative expressivism linked to Robert Brandom's inferentialist theory, which we use to establish an essential connection between having knowledge-or being a possessor of knowledgeand being attributed with having knowledge-or being recognized as a giver of knowledge by third parties and, also, between having knowledge and being an attributor of knowledge. From this point of view, any explanation of the concept of knowledge must consider the social and normative functions that knowledge-attributions play.

We do three things when we ascribe knowledge that $p$ to someone: (i) we attribute the commitment that $p$, (ii) we attribute an entitlement to that commitment, and (iii) we undertake that same commitment ourselves (Brandom 2000, 119). To put it in more classical epistemological terms, we share with the attributee the belief that $p$ and take her to be justified in believing that $p$ or reliably connected to $p$. Thus, when we say that somebody knows that $p$ we are, among other things, conferring a merit on her, conferring a certain normative status on the speaker who is attributed with having knowledge, and attributing the entitlement to the commitment to $p$. Determining the reasons that lead us to conclude that the speaker is worthy of the knowledge-attribution is a matter of a different order, one that transcends the question regarding how the concept works. Whether we conclude that the speaker knows that $p$ by considering, for example, the virtuosity of her practices of belief-formation or by considering the mental states that can be ascribed to her, given her conduct, is a matter for first-order epistemology. The meta-epistemological point of view shows that being a subject of knowledge has to do with being a member of a community, rather than with an isolated individual and her relation to the world (see Navarro-Laespada and Frápolli 2018). In this sense, the normative status that each speaker has in a community is highly relevant for her epistemic standing.

Now, considering that from the first-person perspective it is impossible to distinguish between knowledge and mere belief (see Frápolli 2019; see also note 2 above), it 
turns out that one can attribute an epistemic status only to oneself, or to one's own testimony, parasitically with respect to third-person attributions. We need others to recognize us as knowledge-possessors-by recognizing us as knowledge-givers when we try to communicate our knowledge-in order to recognize ourselves as such. That the first-person perspective is not, ultimately, the perspective from which knowledge-attributions acquire meaning is a semantic or conceptual issue. We need more than one perspective to tell knowledge apart from belief, because knowing that $p$ is to correctly follow a public rule and, as Wittgenstein puts it, "to think one is obeying a rule is not to obey a rule" (Wittgenstein 1953/1968, §202). We have claimed, following Brandom, that attributing knowledge is attributing a true belief as well as taking the subject to be entitled to such a belief. Now, for the attribution of a true belief to be informative, the attributor needs to be able to also attribute false beliefs. Cases where the attributor and the attributee are the same person do not allow for the attribution of false beliefs. If I attribute to myself knowledge that $p$, then I attribute to myself the commitment that $p$ and I acquire that very commitment, so that I cannot say that $p$ is false without contradiction: this is the idea behind the paradoxical nature of Moorean sentences such as "I believe that $p$, but not- $p$ " and Wittgenstein's remark, "If there were a verb meaning 'to believe falsely,' it would not have any significant first person present indicative" (Wittgenstein 1953/1968, part II, X).

Hence, possessing knowledge and being recognizable as a possessor of knowledge by others are conceptually linked. Let's imagine, for a moment, an extreme, hypothetical, and idealized case where a speaker's claims were universally rejected. It is not too farfetched to guess that such a person would end up being psychologically damaged to the point of losing the capacity to distinguish between appearance and reality, between what seemed correct to her and what is correct. If the beliefs the subject forms are not assiduously and consistently confirmed-or corrected-if all her testimonies are denied, rejected, or just ignored, then she may come to doubt her very ability to form correct beliefs. She may, for example, come to doubt her perception as a reliable method of belief-formation or her memory as a provider of reliable premises for reasoning. This could be part of the explanation behind phenomena such as gaslighting. Once again, the point of bringing out this case is conceptual, rather than psychological, and it can be put in terms of the Wittgensteinian analysis of rule-following: the epistemic practices of a community are ruled practices and, for this reason, participating in them requires some training. We need others to train us, that is, to confirm or correct our belief-formation, in order to know if we are properly following the rules. When the training is not consistent enough, our participation in the epistemic practices of the community may go out of synch. Of course, this does not mean that the rules according to which someone knows that $p$ are ideal, invariable, and fact-dependent; their subject matter is ineliminably normative (see Kripke 1982; Field 2009; 2018; Pinedo 2020). What the hypothetical scenario is meant to point out is an aspect of the notion of knowledge that helps to explain why testimonial injustice is epistemic in the secondary sense, even if it does not result in the victim abandoning his belief: if a speaker is able to overcome an episode of testimonial injustice so that it does not cause loss of knowledge, it is precisely because testimonial injustice is not a universal phenomenon, that is, because there are always other hearers who do listen and train the speaker. That is to say, the cases where a speaker overcomes an episode of testimonial injustice through self-attribution of knowledge depend on the situations in which the speaker is recognized as a subject of knowledge by others. 
In real life, for example, as a woman, you are attributed with having knowledge less frequently than male speakers are, but you are attributed with having knowledge sometimes. It could also happen that a speaker is not believed by the mainstream but is believed sufficiently by other persons or groups and manages to retain her belief despite episodes of testimonial injustice. Trying to answer the question of how much recognition is needed for this to happen does not seem a very promising path if attributing with having knowledge is, rather than describing a state of the subject, evaluating and granting her a normative status. As we have said, the extreme case aims at highlighting a conceptual rather than empirical link concerning the unavoidable loss of knowledge suffered by someone whose testimony has been unjustly treated. Although we will show that our argument has important empirical consequences for the standing as possessors of knowledge of victims of testimonial injustice in at least three dimensions (regarding their decreased epistemic agency, their lack of epistemic friction, and their difficulty in occupying certain epistemic nodes), our point is not that every person will suffer all of these harms or even that no person could escape all three if she could mobilize other resources (for instance, finding room for epistemic maneuver within her own oppressed community).

Now, testimonial injustice is not universal, but it is structural and, in the relevant cases, persistent (Fricker 2007, 29). That is, testimonial injustice is part of a broader pattern of injustice with social and economic factors that enhance the epistemic impact on the subject: for instance, not being given proper recognition as a knower will make it even harder for someone with few economic resources or role models to have access to institutions of higher learning. Besides, there are speakers who, in virtue of their social identity, are persistently questioned as subjects of knowledge in most spheres of their lives and, furthermore, the kind of knowledge that they are actually granted is always considered second-class and unskilled. It would be perhaps too optimistic to assume that, in such a predicament, they are likely to overcome the credibility deficit by means of self-attributions of knowledge. In fact, as José Medina points out, it is surely an epistemic virtue to question one's own beliefs when our interlocutors question them (Medina 2013). The objection posed by Origgi and Ciranna, which demands that victims of testimonial injustice ignore the feedback they receive, would force the victims to behave unvirtuously, epistemologically speaking. Therefore, the cases that the objection we are considering presents as counterexamples to the epistemic nature of testimonial injustice, even if possible, can only be marginal cases: they produce epistemic harm to the extent that knowledge is conceptually connected to the recognition of certain entitlements by third parties. The persistent reluctance to give credibility to certain speakers by virtue of their social identity causes them to have a deflated epistemic status, and this is an injustice of a specifically epistemic nature because it makes it difficult for victims to participate in communal practices of exchange and assessment of information. In the following section, we distinguish three forms of epistemic harm in which this handicap could materialize.

We would like to underline two attractive aspects of our view. First, the "attributional" approach to knowledge (that is, the claim that there is a conceptual link between knowledge-possession and knowledge-attribution) has the advantage of being capable of adding an epistemological note to the moral and social diagnoses of testimonial injustice: even where the subject retains her knowledge (either through epistemic heroism or stubbornness, or through the support of a resistant subcommunity that continues to give her credit), the community at large will have done its best to undermine the status of the subject as a possessor of knowledge. Such oppressive efforts will, de facto, 
often lead to epistemic damage in one or more of the three dimensions mentioned above and that we will discuss at length in the following section. We are taking advantage of the ambiguity of "status" deliberately: I may lose my public status as a possessor of knowledge and still be a possessor of knowledge (the epistemic establishment does not recognize me as a credible source of information, even though I am one), this being a different way of phrasing the objection that we are trying to answer. How can we make sense of this possibility and still reject the objection? What does it mean to say that someone possesses knowledge in the face of losing status as a knowledgeable source? At the very least, it means that a properly placed community would attribute knowledge to her. That community may be a real community you have actual access to (for instance, other working-class women who take your claims of sexual harassment at face value, rather than viewing them as a mere expression of prudish discomfort). But the very idea that you could be a subject of knowledge even if no community would ever attribute knowledge to you, which is certainly behind some strong forms of naturalism in epistemology, seems to us completely divorced from most of our epistemic practices. This, to our mind, already goes some way toward establishing the conceptual link behind our attributional account.

Second, our attributional account makes sense of the normative character of knowledge-possession and avoids an additional problem of strongly naturalistic approaches: their commitment to a dubiously atomistic conception of knowledge. One of the most interesting theoretical consequences of the recent focus on the social, ethical, and political aspects of epistemic practices is the displacement, after twenty-five centuries, of "Angela knows that $p$ " as the paradigm of knowledge. The objection that we are tackling seems to partially depend on this assumption: because of my social identity, nobody believes me when I say that I did not steal the bottle of wine, but I do know that I did not steal it. But, even if I retain my belief that $p$ as well as my reasons for it (which, we contend, is a consequence of my having been attributed with having knowledge in other cases or by other people), the three dimensions of the epistemic damage that we discuss may befall other areas of my belief system: I may be forced to have vicious epistemic practices, such as being stubborn, or it may increase the chance that other people won't attribute you with having knowledge in the future, or I may end up taking too seriously the perspectives of others and sacrifice my own (perhaps not with respect to $p$, but with respect to other things). Putting both points together: The idea that by retaining my belief that $p$ I have ipso facto avoided the secondary, purely epistemic damage seems to be committed to finding intelligible: $i)$ that someone could be a knower even if no one would attribute knowledge to her, and ii) that knowing something is independent from the rest of the subject's epistemic network (see Bensusan and Pinedo 2014). ${ }^{5}$

Finally, let us say something about the way in which this understanding of testimonial injustice can be applied to another type of epistemic injustice Fricker discusses: hermeneutical injustice. The line of argument that we are pursuing can also illuminate the epistemic character of situations of hermeneutical injustice, "the injustice of having some significant area of one's social experiences obscured from collective understanding owing to a structural identity prejudice in the collective hermeneutical resource" (Fricker 2007, 155), and shed some light on one criticism that Fricker's understanding of this latter kind of epistemic injustice has received. ${ }^{6}$ Let us think for a moment of the cases in which socially unprivileged groups have actually developed a deep understanding of their own experience, a phenomenon called hermeneutical dissent by Trystan Goetze (Goetze 2018). For instance, regarding Black feminism, Patricia Hill Collins 
argues that African-American women not only managed to retain the knowledge they had despite the discredit they suffered, but they were also able to produce novel conceptualizations of the injustice they are subjected to:

Testifying on one's own behalf within Black feminism not only produced new knowledge from Black women's standpoint, but this exercise of epistemic agency challenged prevailing practices of epistemic injustice. (Collins 2017, 117)

According to Rebecca Mason, being discredited by the mainstream does not necessarily undermine the knowledge of the disadvantaged groups of their own experience, but it constitutes a kind of hermeneutical injustice to the extent that they cannot communicate it to dominant groups who lack such resources (Mason 2011). Mason's critique is as follows. In defining the notion of hermeneutical injustice, Fricker identifies the "collective" hermeneutic resources with the resources upon which dominant discourses are articulated, and this, in addition to ignoring and silencing nondominant interpretive resources, may obscure another kind of hermeneutical injustice consisting in the incapacity to communicate some experiences to those who lack the appropriate resources to understand them. Although Mason's criticism is just that Fricker neglected a particular kind of hermeneutical injustice, it suggests that Fricker's analysis of hermeneutical injustice can lead to the false conclusion that people from non-dominant groups cannot generate concepts and understand their own experiences: ${ }^{7}$

Fricker's analysis of hermeneutical injustice does not take into account the resistant epistemic and communicative practices of non-dominant subjects and in so doing may contribute to their marginalization and disempowerment. Fricker fails to countenance the possibility that marginalized subjects have non-dominant interpretive resources from which they can draw to understand and describe their experiences despite absences or distortions that exist in so-called collective hermeneutical resources. (Mason 2011, 295)

Despite not being recognized by the mainstream, the vulnerable do develop concepts and understand their experiences. Knowledge can be built from the periphery, from disadvantaged social groups, and, even if such knowledge does not reach the mainstream, subjects of epistemic injustice often receive credibility from other members of their own group. This highlights the fictional character of our extreme example above, but more important, it serves to strengthen our point: you need to be recognized, to be attributed with having knowledge, in order to be a subject of knowledge. What the metaepistemological approach suggests here is that the epistemic capacity of a person or group to develop concepts with which to understand and explain their own experiences depends on that person or group having received knowledge-attributions: there is a kind of epistemic progress that can come only from the development, within disadvantaged groups, of new ways to understand their own experience of oppression. This is an especially interesting instance of the phenomenon at the center of our proposal: it is precisely because members of such groups recognize the reality and importance of one another's experiences that they can be such powerful sources of irreplaceable knowledge. ${ }^{8}$ However, as Mason puts it, the incapacity to convey an experience (knowledge) to people belonging to dominant groups because they lack the appropriate resources to understand it also constitutes an epistemic harm, called contributory injustice by Kristie Dotson (Dotson 2012, 31). But, in what sense? A parallel objection that 
we are trying to answer in this article could be raised here: if people can develop conceptual resources to understand their own experience as a form of epistemic resistance from the margins, why does not being understood by the mainstream constitute an epistemic harm, in the pure sense, if the oppressed managed to retain a grasp on the nature of their own experience? Even worse: someone may object that in fact it is the socially powerful who are wronged in the purely epistemic sense, because after all, they have fewer epistemic resources than the vulnerable do (see Medina 2013, 108; and Fricker $2016,174)$. Contributory injustice would not be epistemic in the secondary sense.

Again, we believe the explanation of the epistemic harm in this case is clearer from the theoretical framework that we adopt. To the extent that having knowledge depends on being attributed with having knowledge, the fact that the vulnerable are not attributed with having knowledge by the mainstream because of the lack of conceptual resources to understand the experience that they try to communicate contributes to their lack of knowledge. If we unjustly refrain from attributing knowledge to someone from a socially disadvantaged group, we are contributing as best we can to that person not having knowledge and, although there are empirical cases in which receiving a credibility deficit does not entail loss of knowledge for the victim, not attributing knowledge in cases in which it must be attributed contributes to the rise of cases in which the victim loses her knowledge. After all, epistemic communities of resistance are, by definition, minority communities, placed on the margins of canonical conceptualizations and analyses, and, because of this, they often remain unknown to other victims of the injustice or are seen as eccentric even by them. Overcoming the full force of an unfair epistemic environment is considered, even among the most optimistic proponents of the epistemic superiority of the oppressed (Lukács 1923/1971), to require extremely hard work. As highlighted by Mason's criticism, the knowledge that communities of resistance have tends not to have the echo or influence that mainstream analyses do, which implies that by no means all victims of hermeneutical injustice can benefit from it. Although, fortunately, hermeneutical injustice does not always result in the incapacity to explain one's own experience, we believe that there is also something to be gained in applying to the case of hermeneutical injustice an analogous argument to the one we propose for testimonial injustice. The persistence of hermeneutical injustice favors the emergence of false consciousness among its victims, who in many cases will not have suitable models and may try to explain their experience by using mainstream frameworks that deny them the status of subjects of knowledge. On the other hand, even those who manage to overcome hermeneutical injustice will have to walk a much more winding path to the acquisition and conservation of knowledge than if this injustice had not been done to them. This is a tragic consequence that indicates to what extent epistemic injustice is a serious problem. Epistemic injustice is more than a form of disrespect, and fighting it is more than a matter of etiquette. It is a form of violence that deprives many of its victims - though not all-of the full epistemic development they are capable of. This is why we think we should beware of any optimistic glorification of the epistemic superiority of the victims: even if coming out alive means coming out twice as strong, that would not make the injustice any less damaging or tolerable.

\section{Counting the Ways in Which Testimonial Injustice May Be Epistemic}

We have argued that the purer epistemic character of testimonial injustice does not only depend on the victim's loss of confidence. It also depends, crucially, on what it means to 
attribute knowledge and its conceptual connection with being a subject of knowledge. According to our view, to attribute knowledge to someone is to recognize her as having a normative status, that is, as having certain entitlements to do certain things, like offering testimony, for instance. If we do not receive that kind of recognition, we are not subjects of knowledge, given the link between being a subject of knowledge and receiving knowledge-attributions. Thereby, not attributing knowledge to someone because of their identity contributes to that person being handicapped as a subject of knowledge. In this sense, situations of testimonial injustice have an epistemic character even when the victim retains her belief.

Within this framework, we will highlight three important senses in which the purely epistemic harm resulting from testimonial injustice materializes. Not being recognized as a subject of knowledge in a persistent way may undermine my epistemic agency, may rob me of the necessary epistemic friction, and may make it difficult for me to occupy certain epistemic nodes.

The first sense in which testimonial injustice may cause an epistemic harm focuses on the victim's point of view. According to Roessler, to persistently receive a credibility deficit may undermine self-worth and self-knowledge, and both are prerequisites for epistemic agency. When we are persistently disbelieved, we can feel insecurity and then begin to doubt whether we deserve to participate in the conversation (undermining self-worth) or whether we really believe what we are saying (undermining selfknowledge). Since self-worth and self-knowledge are prerequisites for epistemic agency, to undermine one of them is a way of causing an epistemic harm. The idea is that a person cannot act autonomously, in an epistemic sense, without self-worth or selfknowledge. Roessler argues that the reasons a person has for believing or knowing that $p$ are the same reasons that support her claim that $p$ (sometimes she will claim that $p$ because she takes herself to know that $p$, and other times because she believes that $p$ while falling short of attributing knowledge that $p$ to herself: see note 2 above). If every time this person says $p$ she is questioned, what is being questioned are the same reasons she has to support that she knows or believes that $p$, that is, the reasons that support that she is entitled to have these mental states. Therefore, if discredit occurs systematically and persistently, it is reasonable to think that she will begin to doubt whether she is able to believe or know anything and, in this way, testimonial injustice can undermine self-knowledge (Roessler 2015, 76-77). Within the meta-epistemological approach, Roessler's explanation is complemented by observations about how the verb "to know" behaves logically. As we saw in the previous section, there is a very close relation between attributing and being attributed with having knowledge, on the one hand, and being a subject of knowledge, on the other hand, among other things because of the conceptual commitments linked to action, merit, and recognition that we acquire when we attribute knowledge to someone. The extreme case in which a person is not a subject of knowledge because she has never received credibility or attributions of knowledge shows that being a subject of knowledge is closely linked to, and depends on, other people recognizing you as a knower. Systematically and persistently depriving a person of this recognition can lead to the epistemic damage that Roessler points out.

Although she makes the point in relation to first-person authority, Cristina Borgoni has recently made explicit the link between social acknowledgment and self-knowledge. Her idea, in a nutshell, is that first-person authority and self-knowledge are independent in the following sense: epistemic authority is a social status and, in order to possess it, even regarding one's own mental states, it needs to be recognized by others. Because she also argues that, normally, self-knowledge is retained even in the absence of publicly 
sanctioned first-person authority, she concludes that the latter is not necessary for the former:

In extreme prejudicial scenarios, one's authority can be totally undermined due to the lack of recognition of such an authority by one's peers. This result suggests that firstperson authority necessarily has an attributional element. In contrast, first-personal knowledge does not have such an attributional element. (Borgoni 2019, 297)

The only thing that separates our proposal from hers is that we extend the conceptual link between recognition and authority to self-knowledge.

The second way in which testimonial injustice can be epistemic focuses on the role played by the community. The basic idea is that receiving a credibility deficit in a persistent way may rob the subject of the epistemic friction with the community that is necessary to be a subject of knowledge. That is, we must engage in the public game of asking and giving reasons to evaluate our information, we need friction with the community, we need to contrast our ideas and information with others to gain knowledge. Being a subject of knowledge, from a normativist meta-epistemological approach, necessarily involves grasping the possibility of error (Wittgenstein 1953/1968, \$\$185202) and having the capacity to distinguish between "it is correct" and "it seems correct to me." This capacity is developed within a community by means of different forms of training, punishments, rewards, and so on (see Heras-Escribano, Noble, and Pinedo 2015). What we are calling epistemic friction belongs to that family. If a person persistently receives less credibility than she deserves, then she is being prevented from participating and training in the normal epistemic practices of the community: to be disbelieved may cause a person to desist from participating in these practices, or to participate less frequently and to expose her reasons to public scrutiny less often. This may lead to detachment from the practices and situations that are necessary for knowledge, among them the practices of attributing knowledge to oneself and to others. ${ }^{9}$ To grasp the concept of knowledge and its conceptual connection with our normative commitments and expectations, we need exposure to situations in which these connections are made explicit. Being persistently disbelieved, ignored, or contradicted is a way of denying us the epistemic friction with the community and the participation in the practices necessary to be a competent user of the concept of knowledge and, hence, a subject of knowledge in the full sense.

The third sense in which testimonial injustice is epistemic is derived from the kind of structural approach to testimonial injustice that we favor. That we sometimes do not attribute knowledge to someone because of their social identity can be understood in at least two ways: from a psychological perspective-in terms of individuals' biasesor from a structural approach-in terms of the existence of unjust social norms. Although Fricker's starting point is a situation of structural socioeconomic injustice (epistemic injustice is directed toward members of oppressed and powerless groups in virtue of their membership in such groups), which facilitates testimonial injustice, her diagnosis of the latter kind of injustice is more psychological than structural: prejudices and other forms of bias are central to her understanding of the injustice and to most of the ensuing discussion. In order to prevent testimonial injustices from occurring and to promote more successful testimonial exchanges, Fricker recommends cultivating the virtue of testimonial justice, which consists of blocking the effects of prejudice when considering the testimony of others. This is a kind of individualist 
and psychological intervention, motivated by conceiving testimonial injustice as a result of hearers' identity prejudices and biases (Fricker 2007, 4).

Even though our framework is compatible with both a structural and a psychological explanation of what causes testimonial injustice, its intrinsically social character fits more smoothly with a structural than with a psychological diagnosis. We find two main drawbacks with Fricker's tendency toward psychologism: her idea that testimonial injustice is caused by prejudices and biases on the part of individual hearers makes her position more vulnerable to the objection we consider here, and, furthermore, it makes it more difficult to intervene in order to fight testimonial injustice. So, instead, we sympathize with a structural view such as the one defended by Saray Ayala and Nadya Vasilyeva, according to which testimonial injustice should be understood as the consequence of the correct following of unjust rules (Ayala and Vasilyeva 2015; but see also Haslanger 2015a; 2015b; Ayala 2018). Thus, our claim is that testimonial injustice occurs, not because speakers have perverse biases, but because some of the rules that govern our practices are perverse.

The structural approach is not only less exposed to the epistemic challenge, it also explains a dimension of the harm caused in cases of testimonial injustice that the psychological approach does not and that affects the way in which we understand intervention: the injustice is not limited to the credibility deficit itself, but extends to the social norms that the hearers exploit in disbelieving someone. ${ }^{10}$

According to Sally Haslanger, a social structure is a network of social relations governed by practices (Haslanger 2015a; 2015b; see also Ayala 2018; Ayala and Vasilyeva 2015). These practices locate each person in a specific node of the network. Each node enables those occupying it to do a limited range of things. Thus, to persistently receive a credibility deficit because of social identity makes it difficult to occupy nodes of the network where one is taken to be a subject of knowledge. The idea that there are epistemic nodes whose access is restricted by virtue of unfair norms - sexist, racist, classist, and so on-can account for the cases that Fricker understands as cases where social power operates purely structurally-as opposed to cases where it is exercised by an agentsuch as the lack of interest in politics of certain social groups (Fricker 2007, 10) or the underrepresentation of other groups in certain areas of knowledge. For example, several studies reveal that female students perform worse when tests invoke stereotypes about women's capacity for mathematics (Huguet and Régner 2007). A structural perspective explains this difference in performance as a result of continued exposure to norms such as "women are bad at math," which would dissuade women from engaging in disciplines with a heavy mathematical component.

Although the extreme hypothetical case of someone never given credibility aims at making salient the conceptual connection between being a subject of knowledge and being recognized as a subject of knowledge, the real cases in which a person does not receive credibility from the mainstream but does receive it from the members of some group show that testimonial injustice still produces the triple epistemic injustice that we point out, even if the person manages to maintain her knowledge. First, even if she does not lose her epistemic agency and self-esteem, testimonial injustice paves the way for it (for example, if she had false class consciousness and the recognition of her group was not enough). Second, epistemic friction needs to come from those who do not think like you, and receiving recognition only from your group places you in the same position of epistemic disadvantage of the privileged. Finally, even if a person receives full recognition from her group, some epistemic nodes can be occupied only if one is accepted as a knower by the elite. 


\section{The Harm of Testimonial Injustice is always Epistemic}

As we have seen, although Fricker points out that testimonial injustice is a kind of epistemic injustice, one might reasonably object that the harm caused by testimonial injustice is not epistemic-in a narrow sense of "epistemic" according to which the injustice is epistemic only to the extent that there is loss of knowledge on the part of the victim. Different authors have raised varieties of this objection: if someone who is perceived as less credible because of her identity continues to trust the belief that she was trying to communicate, the harm caused is not epistemic. It can even be argued that it is the perpetrator of the epistemic injustice who suffers the epistemic harm because he ends up knowing less than he would have known if he had believed the speaker. Therefore, testimonial injustice would not always produce epistemic harm: it does so only in those cases where the speaker loses confidence in her belief.

However, we claim that testimonial injustice is always epistemic. Throughout the article, we have argued that, given the conceptual link between being a subject of knowledge and being attributed with having knowledge displayed by the meta-epistemological approach that we endorse, any unfair lack of knowledge-attribution to someone constitutes epistemic harm by itself. This is so because self-attributions of knowledge are asymmetrically dependent on cases in which the self-attributor received credibility and attributions of knowledge from third parties. Our move can be seen as a way of developing Fricker's point according to which losing knowledge is a secondary harm of testimonial injustice because it derives from not being recognized as a reliable source of knowledge, which is the primary harm of testimonial injustice. However, without a successful explanation of the connection between both types of harm, Fricker's diagnosis is exposed to the objection.

In section II, we relied on Brandom's analysis of knowledge-attributions and, in particular, on the idea that when we attribute knowledge to someone, what we are doing is attributing merit, conceptual commitments, and entitlements linked to action, and granting a normative status. If a person is deprived of merit, normative status, and entitlement to actions conceptually linked to "knowing that $p$," then that person cannot be seen as a subject of knowledge. We also present an extreme, fictional case to make explicit the conceptual link between knowledge-attribution and knowledge-possession.

In section III, we pointed out three different ways in which the epistemic harm highlighted by the meta-epistemological analysis can crystallize, and we have shown to what extent this approach enables us to highlight the epistemic character of the injustice in three different senses: testimonial injustice is epistemic inasmuch as it undermines the epistemic agency of the victim, the epistemic friction necessary for knowledge, and the possibility of occupying particular epistemic nodes.

Acknowledgments. We are thankful to Saray Ayala, María José Frápolli, Alba Moreno, Javier Osorio, Neftalí Villanueva, and the anonymous referees of this journal for their valuable comments on early drafts of this article. We would also like to thank the audiences of the 13th Conference of the Italian Society for Analytic Philosophy (SIFA) and the second edition of the FiloLab-International Summer School (FL-ISS), where a previous version of this work was presented, for their questions, suggestions, and comments. The authors have contributed equally to the elaboration of the article and sign in alphabetical order.

This work was funded by the Spanish Ministry of Economy (Project FFI2016-80088-P, FPI Predoctoral Fellow BES-2017- 079933), the Spanish Ministry of Education, Culture, and Sports (FPU16/04185), the Spanish Ministry of Science (PID2019-109764RB-I00), Junta de Andalucía (B-HUM-459-UGR18), and the FiloLab Group of Excellence funded by the University of Granada. 


\section{Notes}

1 Fricker recognizes the existence of testimonial injustices that are merely incidental, that is, not persistent or systematic. These are not linked to other forms of injustice and, in that sense, they do "not render the subject vulnerable to any other kind of injustice (legal, economic, political)" (Fricker 2007, 27). We will focus on nonincidental injustices throughout the article, although our conclusions may extend to incidental testimonial injustices as well.

2 Throughout the article, except when preceded by "mere", we use "belief" in the usual, technical sense: belief is a component of knowledge, as captured by the classic tripartite definition of knowledge as justified true belief. This sense contrasts with the everyday usage, where belief falls short of knowledge, as in "I don't know whether Amalia will come to the party, but I believe she will." Furthermore, we assume that not only losing knowledge, but also diminishing the credence given to one's own beliefs, can be consequences of epistemic injustice (see Gerken 2019).

3 We thank two anonymous referees for forcing us to be clearer on this point.

4 Sometimes we may find it rational to hold onto a belief that we know that it does not amount to knowledge, for instance, because we haven't discarded yet some marginal but relevant possibilities of its being false (see McGlynn 2013). Still, when we do attribute knowledge to ourselves, we have no means to distinguish cases when we actually know from cases where we merely believe that we know. We thank a referee for calling our attention to this possibility.

5 We are grateful to an anonymous referee for forcing us to be more explicit about the role played by the third-person perspective.

6 We are thankful to Saray Ayala for pressing us on this point.

7 See Dotson 2012 for a thesis in this line, a form of unintentionally perpetrating epistemic oppression; see also Pohlhaus 2012.

8 This is very much in line with Medina's insistence on a kind of epistemic privilege that can come only from oppression: the privilege resulting from having to constantly establish the credentials of our beliefs against the resistance of the powerful (see Medina 2013). We deeply sympathize with this idea, and it is part of the inspiration for our argument for the need for epistemic friction in order to have knowledge. 9 Of course, even though the oppressed are deeply exposed to epistemic problems and disadvantages because of this kind of lack of epistemic friction with the community, systematic exposure to unjust epistemic practices can also enable the victim to develop some epistemic advantages and virtues, such as pointed out in the literature on race theory and feminist theory (see Medina 2013,43, and the closing paragraphs of section II of the present article).

10 In fighting against testimonial injustice, we must struggle not only against biases and prejudices, but also against the unjust social norms that produce and perpetuate these prejudices and these injustices themselves. In fact, changing the social norms that people must follow may sometimes be enough to fight against testimonial injustice. Let us consider, for example, the idea that women are not capable of ruling a country. An individualistic intervention would demand that each individual who explicitly or implicitly subscribed to such an idea had to work on their own prejudices and train themselves to correct them. In contrast, intervening structurally could involve selecting a woman as the visible face of the government. Ensuring women's visibility in roles that the unfair norm has reserved for men targets the norm structurally, and it is a kind of intervention that can operate regardless of how virtuous particular individuals are. Needless to say, individual, psychological prejudicial tendencies would become less likely in contexts where fair norms are solidly established, and there is something clearly desirable about moral progress also in the narrow sense of facilitating virtuous psychological dispositions. Our point is that a structural approach would also have a much greater psychological impact.

\section{References}

Ayala, Saray, and Nadya Vasilyeva. 2015. Explaining speech injustice: Individualistic vs. structural explanation. In Proceedings of the 37th annual conference of the Cognitive Science Society, ed. Rick Dale, Carolyn Jennings, Paul P. Maglio, Teenie Matlock, David C. Noelle, Anne Warlaumont, and Jeff Yoshimi. Austin, Texas: Cognitive Science Society.

Ayala, Saray. 2018. A structural explanation of injustice in conversations: It's about norms. Pacific Philosophical Quarterly 99 (4): 726-48. 
Bensusan, Hilan, and Manuel de Pinedo. 2014. I only know that I know a lot: Holism and knowledge. Epistemologia 2: 234-54.

Borgoni, Cristina. 2019. Authority and attribution: The case of epistemic injustice in self-knowledge. Philosophia 47 (2): 293-301.

Brandom, Robert. 2000. Articulating reasons: An introduction to inferentialism. Cambridge, Mass.: Harvard University Press.

Collins, Patricia Hill. 2017. Intersectionality and epistemic injustice. In The Routledge handbook of epistemic injustice, ed. Ian James Kidd, José Medina, and Gaile Pohlhaus Jr. London: Routledge.

Dotson, Kristie. 2012. A cautionary tale: On limiting epistemic oppression. Frontiers: A Journal of Women Studies 33 (1): 24-47.

Engel, Pascal. 2016. La fable de l’injustice épistémique. Unpublished manuscript.

Field, Hartry. 2009. Epistemology without metaphysics. Philosophical Studies 143: 249-90.

Field, Hartry. 2018. Epistemology from an evaluativist perspective. Philosophers' Imprint 18 (12): 1-23.

Frápolli, María José. 2019. The pragmatic Gettier: Brandom on knowledge and belief. Disputatio: Philosophical Research Bulletin 8 (9). https://zenodo.org/record/4611293\#.YSP2batKiX0.

Fricker, Miranda. 2007. Epistemic injustice: Power and the ethics of knowing. Oxford: Oxford University Press.

Fricker, Miranda. 2016. Epistemic injustice and the preservation of ignorance. In Epistemic dimensions of ignorance, ed. Rik Peels and Martijn Blaauw. Cambridge, UK: Cambridge University Press.

Gerken, Mikkel. 2019. Pragmatic encroachment and the challenge from epistemic injustice. Philosophers' Imprint 19 (15): 1-19.

Goetze, Trystan. 2018. Hermeneutical dissent and the species of hermeneutical injustice. Hypatia 33 (1): 73-90.

Haslanger, Sally. 2015a. What is a (social) structural explanation? Philosophical Studies 173 (1): 113-30.

Haslanger, Sally. 2015b. Distinguished lecture: Social structure, narrative and explanation. Canadian Journal of Philosophy 45 (1): 1-15.

Hawley, Katherine. 2011. Knowing how and epistemic injustice. In Knowing how: Essays on knowledge, mind, and action, ed. John Bengson and Marc A. Moffett. Oxford: Oxford University Press.

Heras-Escribano, Manuel, Jason Noble, and Manuel de Pinedo. 2015. Enactivism, action and normativity: A Wittgensteinian analysis. Adaptive Behavior 23 (1): 20-33.

Huguet, Pascal, and Isabelle Régner. 2007. Stereotype threat among schoolgirls in quasi-ordinary classroom circumstances. American Psychological Association 99 (3): 545-60.

Kripke, Saul. 1982. Wittgenstein on rules and private language. Oxford: Blackwell.

Lukács, Georg. 1923/1971. History and class consciousness: Studies in Marxist dialectics. Trans. Rodney Livingstone. London: Merlin Press.

Mason, Rebecca. 2011. Two kinds of knowing. Hypatia 26 (2): 294-307.

McGlynn, Aidan. 2013. Believing things unknown. Nô̂s 47 (2): 385-407.

Medina, José. 2013. The epistemology of resistance: Gender and racial oppression, epistemic injustice, and the social imagination. Oxford: Oxford University Press.

Navarro-Laespada, Llanos, and María José Frápolli. 2018. Inferentialism, representationalism, and moral responsibility. In Proceedings of the IX conference of the Spanish Society of Logic, Methodology and Philosophy of Science, ed. Cristian Saborido, Sergi Oms, and Javier González. Madrid: Spanish Society of Logic, Methodology and Philosophy of Science.

Origgi, Gloria, and Serena Ciranna. 2017. Epistemic injustice: The case of digital environments. In The Routledge handbook of epistemic injustice, ed. Ian James Kidd, José Medina, and Gaile Pohlhaus Jr. London: Routledge.

Pinedo, Manuel de. 2020. Ecological psychology and enactivism: A normative way out from ontological dilemmas. Frontiers in Psychology 11:1637. doi:10.3389/fpsyg.2020.01637.

Pohlhaus Jr., Gaile. 2012. Relational knowing and epistemic injustice: Toward a theory of willful hermeneutical ignorance. Hypatia 27 (4): 715-35.

Pohlhaus Jr., Gaile. 2014. Discerning the primary epistemic harm in cases of testimonial injustice. Social Epistemology: A Journal of Knowledge, Culture and Policy 28 (2): 99-114.

Pohlhaus Jr., Gaile. 2017. Varieties of epistemic injustice. In The Routledge handbook of epistemic injustice, ed. Ian James Kidd, José Medina, and Gaile Pohlhaus Jr. London: Routledge.

Roessler, Beate. 2015. Self-knowledge and communication. Philosophical Explorations 18 (2): $153-68$. 
Wittgenstein, Ludwig. 1953/1968. Philosophical investigations. 3rd ed. Trans. G. E. M. Anscombe. New York: Macmillan.

Manuel Almagro Holgado holds a PhD in philosophy from the University of Granada, Spain, where he enjoys a post-doctoral fellowship. His primary interests are in philosophy of language, philosophy of mind, experimental philosophy, and social epistemology. His current research includes the evaluative use of language, mental state ascriptions, disagreement, political polarization, and Wittgenstein's philosophy. He is especially interested in the relationship between these topics and practical issues such as social injustice and polarization in attitudes. malmagro@ugr.es

Llanos Navarro Laespada is a $\mathrm{PhD}$ candidate in philosophy at the University of Granada. Her main areas of interest are the philosophy of language and epistemology, with a particular focus on nonrepresentationalist accounts of meaning and their applications to ethical and epistemic discourses. She is a member of the organizing committee of SWIP-Analytic Spain. llanosnavarro@ugr.es

Manuel de Pinedo García holds a DPhil in philosophy and cognitive science (University of Sussex, 2000) and is a senior lecturer in philosophy at the University of Granada, Spain. His research focuses on epistemology and the philosophy of mind and cognition from a social and political perspective. He leads the Philosophy and Analysis Group (aka Granada Gang). He has recently published on normative approaches to cognition and perception, on social know-how, and on unreflective situated behavior. pinedo@ugr.es

Cite this article: Almagro Holgado M, Navarro Laespada L, de Pinedo García M (2021). Is Testimonial Injustice Epistemic? Let Me Count the Ways. Hypatia 36, 657-675. https://doi.org/10.1017/hyp.2021.56 